\title{
Actividad antimicrobiana de diferentes extractos obtenidos a partir de la vieira patagónica (Zygochlamys patagonica)
}

\author{
Andrea L. SALOMONE* \\ Instituto Nacional de Investigación y Desarrollo Pesquero (INIDEP), Paseo Victoria Ocampo No 1, Escollera Norte, B7602HSA - \\ Mar del Plata, Argentina
}

Marine and

Fishery Sciences

MAFIS

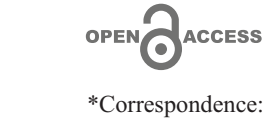

asalomone@inidep.edu.ar

Received: 23 April 2020

Accepted: 30 June 2020

ISSN 2683-7595 (print) ISSN 2683-7951 (online)

https://ojs.inidep.edu.ar

Journal of the Instituto Nacional de Investigación y Desarrollo Pesquero (INIDEP)

This work is licensed under a Creative Commons AttributionNonCommercial-ShareAlike 4.0 International License
RESUMEN. El uso excesivo de antibióticos en medicina, producción animal, agricultura y alimentos, ha contribuido a la aparición de patógenos resistentes a los antibióticos convencionales, haciendo necesaria la búsqueda de nuevos compuestos a partir de fuentes naturales y seguras. Ciertos péptidos de bajo peso molecular, con potencial actividad antimicrobiana, poseen alta especificidad para organismos procariotas y baja o nula toxicidad para los eucariotas. Los invertebrados marinos son una fuente posible para su obtención, ya que poseen un sistema inmune innato muy efectivo el cual es la primera línea de defensa frente a bacterias, hongos y virus. Una forma de obtenerlos es mediante la extracción con diferentes tipos de solventes que permiten mantener la función efectora de estas moléculas luego de su aislamiento. En este trabajo, a partir ejemplares de Zygochlamys patagonica se obtuvieron extractos con diferentes solventes y se compararon los rendimientos con el método control para la aislación de péptidos y proteínas. Se evaluó la concentración inhibitoria mínima (CIM) y la actividad antimicrobiana por medio de la determinación del porcentaje de inhibición del crecimiento de todos los extractos obtenidos sobre bacterias Gram positivas y Gram negativas, y se comparó su eficacia con un antibiótico comercial de amplio espectro. La CIM de los extractos provenientes de los tejidos de vieira ( $\sin$ callos) fue de $2,5 \mathrm{mg} \mathrm{m}^{-1}$, y la actividad antimicrobiana de los mismos fue comparable a la del antibiótico comercial de amplio espectro. De acuerdo con los resultados obtenidos, se recomienda utilizar etanol como método de extracción debido a su menor toxicidad y casi nula posibilidad de contaminación bacteriana durante el proceso. La identificación de estos péptidos podría contribuir a una futura aplicación biotecnológica.

Palabras clave: Péptidos antimicrobianos, bivalvos, vieira patagónica.

Antimicrobial activity of different extracts obtained from Patagonian scallop (Zygochlamys patagonica)

ABSTRACT. The excessive use of antibiotics in medicine, animal production, agriculture and food has contributed to the emergence of pathogens resistant to conventional antibiotics, making the search for new compounds from natural and safe sources necessary. Certain low molecular weight peptides with potential antimicrobial activity have high specificity for prokaryotic organisms and low or no toxicity to eukaryotes. Marine invertebrates are a tentative source for obtaining them, since they have a very effective innate immune system which is the first line of defense against bacteria, fungi and viruses. One way to obtain them is by extraction with different types of solvents, which allow maintaining the effector function of these molecules after their isolation. In this work, extracts with different solvents were obtained from Zygochlamys patagonica and yields were compared to those achieved by the isolation control method for peptides and proteins. Minimum inhibitory concentration (MIC) and antimicrobial activity were evaluated by determining the percentage of growth inhibition of all extracts obtained on Gram-positive and Gram-nega- 
tive bacteria, and their efficacy was compared with a conventional antibiotic. MIC of the extracts from scallop tissues (without calluses) was $2.5 \mathrm{mg} \mathrm{ml}^{-1}$, and their antimicrobial activity was comparable to that of a commercial broad-spectrum antibiotic. According to the results, it is recommended to use ethanol as an extraction method due to its lower toxicity and almost zero possibility of bacterial contamination during the process. The identification of these peptides could contribute to a future biotechnological application.

Key words: Antimicrobial peptides, bivalves, Patagonian scallop.

\section{INTRODUCCIÓN}

Los antibióticos constituyen un grupo heterogéneo de sustancias que ejercen una acción específica sobre alguna estructura o función metabólica de un determinado microorganismo. En los últimos años, el uso excesivo e incontrolado de antibióticos en medicina, producción animal, agricultura y en la conservación de productos alimenticios, ha contribuido en gran medida a la aparición de patógenos resistentes a los antibióticos convencionales. Frente a esta problemática, la búsqueda de nuevos antibióticos se ha convertido en un gran desafío para la biotecnología y la industria farmacéutica, existiendo un gran interés en encontrar este tipo de moléculas a partir de fuentes naturales y ecológicamente seguras (Kim y Mendis 2006; Shahidi y Zhong 2008; Lordan et al. 2011; Najafian et al. 2012; Bahar y Ren 2013; Wang et al. 2017).

Una clase de moléculas que poseen actividad antimicrobiana son los péptidos de bajo peso molecular, que pueden ser naturales (Sharma et al. 2009; Sugesh y Mayavu 2013; Boullet et al. 2019), sintéticos o generados a partir de diferentes procesos de hidrólisis, tanto química como enzimática (Ryan et al. 2011; Ennaas et al. 2015; Hou et al. 2017; Salomone y Massa 2018). Diversos estudios muestran que la mayoría de estos péptidos poseen funciones antimicrobianas (bactericidas o bacteriostáticas) contra varias cepas Gram negativas y positivas, siendo potencialmente útiles en la industria alimentaria y en la farmacéutica. En la actualidad, los péptidos antimicrobianos son algunas veces preferidos a los antibió- ticos convencionales para uso medicinal y alimentario debido a que eliminan las bacterias más rápidamente, su actividad no se ve afectada por los mecanismos de resistencia a los antibióticos, poseen alta especificidad para organismos procariotas y baja o nula toxicidad para los eucariotas (Shahidi y Zhong 2008; Najafian y Babji 2012).

Estos péptidos son moléculas anfifílicas o anfipáticas menores a $10 \mathrm{kDa}$ con alto contenido de lisina y arginina que les confieren carga neta positiva (Tincu y Taylor 2004; Hancock el al. 2006; Lemus et al. 2016; Kuppusamy et al. 2019). Uno de los mecanismos de acción por el cual estas moléculas ejercen su función sobre los microorganismos, se debe a la unión de su carga neta positiva con la carga neta negativa de la superficie lipídica microbiana a través de interacciones electrostáticas que permeabilizan la membrana bacteriana. Estas interacciones provocan un desplazamiento de cationes divalentes $\left(\mathrm{Mg}^{+2}\right.$ y $\mathrm{Ca}^{+2}$ ), facilitando la formación de áreas desestabilizadas en la membrana y promoviendo la translocación del péptido a su interior. De esta manera, inducen la lisis celular directa o la perturbación de la membrana permitiendo la salida de componentes celulares (Gutiérrez y Orduz 2003; Kuppusamy et al. 2019).

Los organismos marinos son un importante recurso para la obtención de moléculas bioactivas. En particular los invertebrados, que poseen un sistema inmune innato muy efectivo el cual es la primera línea de defensa frente a bacterias, hongos y virus. Es un mecanismo de reconocimiento de patógenos poco específico, que genera respuestas tanto a nivel celular como humoral, en donde los péptidos de bajo peso molecular son su principal defensa frente a potenciales patógenos. 
Cuando se dispara la inmunidad humoral, se sintetizan componentes antimicrobianos, siendo los péptidos los que se encuentran en mayor proporción. En moluscos bivalvos, éstos se encuentran en la hemolinfa y en tejidos y órganos que están expuestos a potenciales patógenos (Tincu y Taylor 2004; Sharma et al. 2009; Bahar y Ren 2013; Sugesh y Mayavu 2013). Estos péptidos antimicrobianos pueden estar codificados en el genoma o generarse como metabolito secundario. Por lo general se sintetizan como propéptidos que, luego de activarse, adoptan una estructura secundaria que les confiere su función efectora. Debido a esto, es importante aislarlos en su conformación natural a fin de que los métodos utilizados para su aislamiento no alteren la conformación que poseen dentro del organismo.

Las proteínas y péptidos pueden ser extraídos por diferentes métodos: agitación con abrasivos, homogeneización a alta presión, extrusión, shock osmótico, ciclos de congelación y descongelación, sonicación, extracciones con álcalis, detergentes, ácidos y sustancias caotrópicas. Sin embargo, este tipo de métodos llevan a la obtención de moléculas en forma desnaturalizada, siendo necesarios pasos posteriores para volver a obtener su conformación nativa (Tan y Yiap 2009). Otra forma de obtener péptidos naturales con potencial función antimicrobiana es mediante su extracción con diferentes tipos de solventes (Sharma et al. 2009; Sugesh y Mayavu 2013; Kiran et al. 2014; Injal et al. 2016; Abouzeed et al. 2018). La elección del proceso de extracción con solventes se basa en que, dependiendo de la temperatura y del solvente utilizado, se pueden extraer los péptidos de forma tal que no sufran modificaciones estructurales con respecto a la conformación que poseen naturalmente en un determinado organismo, manteniendo su función efectora intacta (Tincu y Taylor 2004; Hancock el al. 2006; Lemus et al. 2016; Kuppusamy et al. 2019).

Una de las pesquerías certificadas más importantes a nivel comercial en la Argentina es la de vieira patagónica (Zygochlamys patagonica), que cumple con la Norma de Sostenibilidad y Conservación del Ambiente (www.msc.org). Sin embrago, durante el procesamiento de las capturas para la producción de callos congelados en los buques pesqueros, se genera una gran cantidad de biomasa de descarte, que si no es tratado adecuadamente contribuyen a la contaminación ambiental (Schwartz y Campodónico 2017; Campodónico et al. 2019).

El funcionamiento del sistema inmunológico de bivalvos, la problemática ambiental relacionada con los descartes de la pesquería de Z. patagonica y la capacidad bioactiva de péptidos que fueron aislados en otras especies de bivalvos (Sharma et al. 2009; Bahar y Ren 2013; Sugesh y Mayavu 2013; Pachaiyappan et al. 2014), se combinan en este trabajo como punto de partida para la obtención de estas moléculas bioactivas con propiedades antimicrobianas. Para esto, se realizaron extracciones de péptidos utilizando diferentes solventes a partir de dos subgrupos de tejidos de Z . patagonica. Se compararon los rendimientos de cada extracto, y se evaluó la actividad antimicrobiana de los mismos con respecto a un método control para el aislamiento de péptidos y proteínas. Finalmente, se evaluó la actividad antimicrobiana de todos los extractos sobre cuatro especies bacterianas utilizando un antibiótico comercial como control.

\section{MATERIALES Y MÉTODOS}

\section{Obtención de extractos}

Los ejemplares de Z. patagonica utilizados para realizar los extractos fueron recolectados durante 2018 por los buques comerciales "Miss

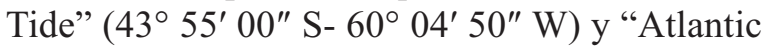
Surf III" ( $45^{\circ} 00^{\prime} 30^{\prime \prime}$ S- $\left.60^{\circ} 15^{\prime} 00^{\prime \prime} \mathrm{W}\right)$. Las vieiras se mantuvieron en cautiverio en acuarios con filtros biológicos a $7 \pm 1{ }^{\circ} \mathrm{C}$. A medida que se iban produciendo las muertes de forma natural, 
los ejemplares se almacenaron a $-20{ }^{\circ} \mathrm{C}$ para representar lo mejor posible el tratamiento durante su procesado. Al momento de su utilización, ocho vieiras fueron descongeladas a temperatura ambiente, lavadas con agua destilada estéril, y posteriormente los callos fueron separados del resto de los tejidos blandos. Se homogeneizaron separadamente los callos por un lado y el resto de los tejidos por otro, para finalmente someter a ambos grupos a las extracciones con los diferentes solventes, conformando así dos subgrupos de tejidos.

Las extracciones se llevaron a cabo con etanol, metanol, acetona y agua por maceración en recipientes de vidrio color ámbar durante cinco días a $25{ }^{\circ} \mathrm{C}$, utilizando $0,5 \mathrm{~g}$ de muestra húmeda por cada $1 \mathrm{ml}$ de solvente, homogeneizando manualmente los tejidos periódicamente. Los homogenatos se filtraron con papel Whatman $\mathrm{N}^{\mathrm{o}} 1$, se recolectaron los eluatos y se evaporaron los solventes en estufa a $60 \pm 1{ }^{\circ} \mathrm{C}$ hasta peso constante (modificado de Injal et al. 2014; Kiran et al. 2014; Pachaiyappan et al. 2014; Abouzeed et al. 2018). Como método de referencia y control positivo de las extracciones, se utilizó ácido ácético para su solubilización (compatible químicamente con la acetona), y la posterior precipitación con acetona para su purificación $(\mathrm{A} / \mathrm{Ac})$. Para esto, se utilizó $0,75 \mathrm{~g}$ de muestra húmeda por cada $1 \mathrm{ml}$ de ácido acético al $10 \%$, se incubó por $24 \mathrm{~h} \mathrm{a} 4 \pm 1{ }^{\circ} \mathrm{C}$ y se centrifugó a $11.400 \mathrm{~g}$ durante $15 \mathrm{~min}$. El sobrenadante se traspasó a un tubo limpio, se le agregó 3 volúmenes de acetona fría, se incubó por 24 h a 4 $\pm 1{ }^{\circ} \mathrm{C}$ y se centrifugó a $5.700 \mathrm{~g}$ durante $15 \mathrm{~min}$ (modificado de Niu et al. 2019). El precipitado obtenido se secó en estufa a $60 \pm 1{ }^{\circ} \mathrm{C}$ hasta peso constante. Los sólidos recuperados con cada solvente fueron solubilizados en dimetilsulfóxido (DMSO) puro para obtener una concentración final de $15 \mathrm{mg} \mathrm{ml}^{-1}$, se esterilizaron mediante filtración con filtro de $0,22 \mu \mathrm{m}$ y se conservaron a $20 \pm 1{ }^{\circ} \mathrm{C}$ hasta su uso. Todas las extracciones se realizaron por duplicado y el rendimiento se expresó como g de sólidos/g de tejido húmedo.

\section{Electroforesis en gel de agarosa}

La separación electroforética de proteínas y péptidos se llevó a cabo en gel de agarosa al 5\% (500 mM trizma base; $160 \mathrm{mM}$ ácido bórico; $1 \mathrm{M}$ Urea; $5 \%$ agarosa; $\mathrm{pH}$ 8.5) en un dispositivo de electroforesis horizontal. La corrida electroforética se realizó en buffer TBS (90 mM trizma base; $90 \mathrm{mM}$ ácido bórico; 0,1\% SDS; pH 8,5) durante $4 \mathrm{~h}$ a $60 \mathrm{~V}$, con refrigeración. Las muestras y las proteínas puras utilizadas como marcadores de peso molecular fueron mezcladas con buffer de siembra 2X (126 mM Trizma Base; 4\% SDS; $0,002 \%$ azul de bromofenol; $15 \%$ glicerina; $10 \%$ ditiotreitol), calentadas a $90{ }^{\circ} \mathrm{C}$ durante $10 \mathrm{~min}$ y mantenidas a $-20 \pm 1{ }^{\circ} \mathrm{C}$ hasta su uso. El gel fue teñido durante $1 \mathrm{~h}(0,25 \%$ Coomasie Blue; 40\% metanol; $10 \%$ ácido acético), y se reveló con varios lavados en solución de decoloración (20\% metanol; 5\% ácido acético) durante toda la noche (Wu y Kusukawa 1998; Kim et al. 2000; Kafle et al. 2018; Lonza Research, 2019).

\section{Ensayo de actividad antimicrobiana en medio líquido. Determinación de la concentración inhibitoria mínima}

La concentración inhibitoria mínima (CIM) se define como la menor dilución de una determinada sustancia en la cual no se observa crecimiento de microorganismos. Para determinarla, se evalúo la capacidad antimicrobiana de cada extracto sobre diferentes especies bacterianas Gram positivas y negativas disponibles en el cepario del Gabinete de Genética Molecular y Microbiología del Instituto Nacional de Investigación y Desarro1lo Pesquero (INIDEP) mediante el método estándar recomendado por la CLSI (Clinical and Laboratory Standards Institute) basado en Geis et al. (1983). El ensayo se efectuó en microplacas de cultivo de 96 pocillos con fondo en $\mathrm{U}$, en un volumen final de $200 \mu \mathrm{l}$, con medio de cultivo LB (extracto de levadura $0,5 \%$; Peptona $1 \%$; cloruro de sodio $1 \% ; \mathrm{pH}=7$ ). Se realizaron diluciones 
seriadas 1:2 de la solución de los extractos a evaluar, de manera que la concentración inicial en el primer pocillo fue $5 \mathrm{mg} \mathrm{ml}^{-1}$. En cada pocillo se inocularon los diferentes cultivos bacterianos: Bacillus subtilis, Esherichia coli, Lactobacillus plantarum y Pseudomona aeruginosa, para obtener una concentración final de $1 \times 10^{4} \mathrm{UFC} \mathrm{ml}^{-1}$ (Unidades Formadoras de Colonias). Se incluyeron los siguientes controles: negativos (Medio LB, $1 \times 10^{4} \mathrm{UFC} \mathrm{ml}^{-1}$; Medio LB, $1 \times 10^{4} \mathrm{UFC} \mathrm{ml}^{-}$ 1 , DMSO); positivo (LB, $1 \times 10^{4} \mathrm{UFC} \mathrm{ml}^{-1}$, Ampicilina $5 \mathrm{mg} \mathrm{ml}^{-1}$ ) y de contaminación (Medio LB; Medio LB, extractos). Las placas fueron incubadas a $37 \pm 1{ }^{\circ} \mathrm{C}$ durante $24 \mathrm{~h}$. Los ensayos se realizaron por duplicado y se determinó la CIM por observación a simple vista del crecimiento, o no, del microorganismo evaluado. Para confirmar la CIM y además calcular el porcentaje de inhibición del crecimiento, se escalaron los ensayos a un volumen final de $5 \mathrm{ml}$ con incubación por 24 h a $37 \pm 1{ }^{\circ} \mathrm{C}$ y agitación a $250 \mathrm{rpm}$, incluyendo los mismo controles detallados en el párrafo anterior. Se midió la densidad óptica (DO) a una longitud de onda de $600 \mathrm{~nm}$ y los resultados se expresaron como la media de los duplicados \pm desvío estándar.

\section{Cálculo del porcentaje de inhibición del creci- miento}

Para comparar la capacidad antimicrobiana de los extractos que presentaron actividad con respecto a un antibiótico convencional a las $24 \mathrm{~h}$ de cultivo, se calculó el porcentaje de inhibición del crecimiento de cada extracto con respecto al antibiótico comercial ampicilina $\left(5 \mathrm{mg} \mathrm{ml}^{-1}\right)$ como control positivo, mediante la fórmula:

$\% \mathrm{IC}=[(\mathrm{A}-\mathrm{B}) / \mathrm{A}] \times 100$

dónde:

$\mathrm{A}=\mathrm{DO}_{600}$ del cultivo bacteriano sin el extracto a ensayar o sin ampicilina;
$\mathrm{B}=\mathrm{DO}_{600}$ del cultivo bacteriano con el extracto a ensayar o con ampicilina.

\section{Análisis estadísticos}

Los análisis se llevaron a cabo utilizando el software GraphPad Prism (GraphPad Software, La Jolla California USA). Todos los ensayos se realizaron por duplicado y fueron analizados mediante ANOVA, con un intervalo de confianza del $95 \%(\mathrm{p}<0,05)$ y se expresaron como la media \pm DE. Luego de haber rechazado la hipótesis nula de igualdad de medias mediante el análisis ANOVA, para la comparación de los rendimientos de sólidos extraídos y de los porcentajes de inhibición se utilizó el Test de Comparaciones Múltiples de Dunnett (1955), que compara el resultado de cada tratamiento con un único control. Los intervalos de confianza utilizados fueron de $95 \%$ para el análisis de los rendimientos (p $<0,05$ ), siendo el tratamiento control el método de extracción con ácido acético/acetona; y de 99,9\% para el análisis de los porcentajes de inhibición del crecimiento bacteriano $(\mathrm{p}<0,001)$, donde el tratamiento control fue el antibiótico comercial ampicilina.

\section{RESULTADOS Y DISCUSIÓN}

En este trabajo se compararon las actividades de péptidos que fueron extraídos con diferentes solventes con respecto a los extraídos por un método control, y a su vez con la actividad antimicrobiana de un antibiótico convencional.

Cuando se compararon los rendimientos de las extracciones de los tejidos sin callos con respecto al método control (A/Ac), no se encontraron diferencias significativas entre las extracciones con metanol y etanol, mientras que el rendimiento de sólidos utilizando agua y acetona resultaron menores (Tabla 1). En el caso de los callos, no hay diferencia significativa entre ninguno de los 
Tabla 1. Rendimiento de las extracciones de sólidos de tejidos de Zygochlamys patagonica utilizando distintos solventes. Comparación respecto al control (ácido acético/acetona) mediante el test de Dunnett (1955). n.s.: no se encuentran diferencias $(\mathrm{p}<0,05)$; $(-)$ : menor rendimiento con respecto al control $(*)$. Los datos se expresan como g de sólidos recuperados/g de peso húmedo de tejido inicial (media $\pm \mathrm{DE})$.

Tabla 1. Yield of solid extractions from Zygochlamys patagonica tissues using different solvents. Comparison with respect to the control (acetic acid/acetone) by Dunnett test (1955). n.s.: no differences found ( $p<0.05)$; (-): lower performance with respect to the control (*). Data are expressed as $g$ of solids recovered/g of initial tissue wet weight (mean $\pm S D)$.

\begin{tabular}{lccccc}
\hline & Metanol & Etanol & Acetona & Agua & Ácido acético/acetona* \\
\hline Tejidos s/ callos & $0,0224 \pm 0,0020$ & $0,0148 \pm 0,0004$ & $0,0113 \pm 0,0010$ & $0,0105 \pm 0,0020$ & $0,0178 \pm 0,0013$ \\
n.s. & n.s. & $(-)$ & $(-)$ & \\
Callos & $0,0184 \pm 0,0007$ & $0,0143 \pm 0,0012$ & $0,0121 \pm 0,0016$ & $0,0131 \pm 0,0040$ & $0,0157 \pm 0,0090$ \\
& n.s. & n.s. & n.s. & n.s. & \\
\hline
\end{tabular}

cuatro métodos de extracción con respecto al control (Tabla 1).

Varios métodos son utilizados para evaluar la actividad antimicrobiana de diferentes compuestos mediante la determinación de la CIM. Dentro de estos métodos se encuentran el ensayo de difusión en agar, la técnica de difusión en disco y el ensayo en microplaca de cultivo (CLSI 2012). Este último fue utilizado en este trabajo, ya que no solo presenta menor error en la lectura visual, sino que puede confirmarse la CIM por espectrofotometría cuando se realiza el ensayo en un volumen mayor. La combinación de estos métodos de lectura dieron como resultado que todos los extractos obtenidos a partir de los tejidos sin callos de $Z$. patagonica presentaron actividad antimicrobiana frente E. coli, B. subtilis, L. plantarum y $P$. aeruginosa, donde la CIM para todos los casos fue de $2,5 \mathrm{mg} \mathrm{ml}^{-1}$, mismo valor obtenido luego de escalar los ensayos (Figura 1). El hecho de que los extractos obtenidos con metanol, etanol, acetona y agua se hayan comportado de la misma manera que el obtenido utilizando el método control, que es específico para la extracción de péptidos y proteínas, permite interpretar que todos ellos mayormente contienen péptidos de bajo peso molecular (Figura 2), y que los mismos son los responsables de la actividad antibacteriana. Estos resultados son consistentes con los reportados por otros autores utilizando como materia prima otros bivalvos. Pachaiyappan et al. (2014) obtuvieron diferentes extractos utilizando solventes polares y no polares en Meretrix casta, los cuales presentaron actividad antimicrobiana frente a bacterias patógenas y no patógenas. A partir de extractos acuosos de M. meretrix, Injal et al. (2016) demostraron la capacidad antibacteriana frente a Salmonella typhi y Staphylococcus aureus, dos especies patógenas en humanos. También presentaron actividad antibacteriana sobre bacterias Gram positivas y negativas los extractos obtenidos con metanol y buffer fosfato a partir de cinco especies distintas de bivalvos comestibles (Sharma et al. 2009).

Todos los extractos obtenidos a partir de los tejidos sin callos no mostraron diferencias significativas cuando se compararon sus porcentajes de inhibición del crecimiento con respecto al antibiótico comercial $(\mathrm{p}<0,001)$ (Tabla 2$)$, indicando que todos los procesos de extracción fueron capaces de obtener los péptidos sin alterar la función inmunológica que realizaban en el organismo del que fueron obtenidos, ya que el método control no altera la conformación original de las proteínas y péptidos extraídos.

Cuando los ensayos se realizaron utilizando los extractos obtenidos a partir del tejido muscular de los callos, ninguno fue capaz de inhibir el creci- 



Figura 1. Actividad antimicrobiana de los extractos obtenidos a partir de tejidos de vieiras (sin callos). Concentración inhibitoria mínima determinada por absorbancia $600 \mathrm{~nm}$. Media de los duplicados \pm DE. Me: metanol, Et: etanol, Ac: acetona, Ag: agua, A/Ac: ácido acético/acetona, Amp: ampicilina, control positivo, OD: densidad óptica.

Figure 1. Antimicrobial activity of extracts obtained from scallop tissues (without muscle). Minimum inhibitory concentration determined by absorbance $600 \mathrm{~nm}$. Mean of duplicates \pm SD. Me: methanol, Et: ethanol, Ac: acetone, Ag: water, A/Ac: acetic acid/acetone, Amp: ampicillin, positive control, OD: optical density. 
A

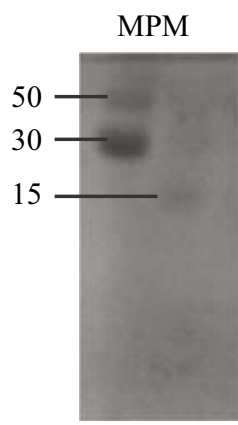

$\mathrm{A} / \mathrm{Ac}$



B

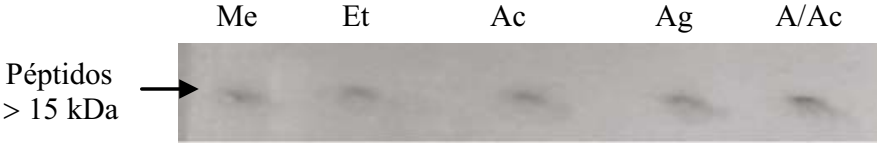

Figura 2. Electroforesis en Gel de Agarosa al 5\% de los péptidos obtenidos. A) Método de extracción control. MPM: marcadores de peso molecular $(\mathrm{kDa})$. B) Péptidos obtenidos con los diferentes solventes. Me: metanol, Et: etanol, Ac: acetona, Ag: agua, A/Ac: ácido acético/acetona (control).

Figure 2. Agarose Gel Electrophoresis 5\% of peptides obtained. A) Control extraction method. MPM: molecular weight markers (kDa). B) Peptides obtained with different solvents. Me: methanol, Et: ethanol, Ac: acetone, Ag: water, A/Ac: acetic acid/acetone (control).

Tabla 2. Porcentaje de inhibición del crecimiento causado por los péptidos obtenidos según el solvente utilizado para su extracción comparado con el antibiótico control (*).

Table 2. Growth inhibition percentage caused by peptides obtained according to the solvent used for their extraction compared to the control antibiotic $(*)$.

Esherichia coli Bacillus subtilis Lactobacillus plantarum Pseudomona aeruginosa

$\begin{array}{lrrrr}\text { Ampicilina* } & 100,00 & 100,00 & 100,00 & 100,00 \\ \text { Metanol } & 99,55 & 99,75 & 99,95 & 99,90 \\ \text { Etanol } & 99,70 & 99,60 & 99,20 & 99,55 \\ \text { Acetona } & 99,65 & 99,70 & 99,95 & 99,70 \\ \text { Agua } & 99,45 & 99,55 & 99,75 & 99,60 \\ \text { Ácido acético/acetona } & 99,85 & 99,35 & 99,95 & 99,60\end{array}$

miento de los distintos cultivos bacterianos (Figura 3). Esta diferencia de comportamiento de los extractos dependiendo de los tejidos que le dieron origen, coincide con resultados de otros trabajos en que la fuente mayoritaria de péptidos con actividad antimicrobiana en bivalvos proviene de hemocitos, epitelios, intestino y órganos respiratorios, donde estos péptidos son su principal línea de defensa contra patógenos (Tincu y Taylor 2004; Sumita et al. 2009; Bahar y Ren 2013; Sugesh y Mayavu 2013). Los resultados obtenidos brindan una alternativa para el uso del material de descarte de la pesca, realizándose de esta forma un aprovechamiento integral del recurso junto con la promoción de una industria amigable con el medioambiente.

\section{CONCLUSIONES}

En este trabajo se evaluó la actividad antimicrobiana de péptidos que fueron extraídos de dos subgrupos de tejidos de vieira patagónica, utilizando diversos solventes. La actividad antimicrobiana de los extractos provenientes de los tejidos sin incluir 

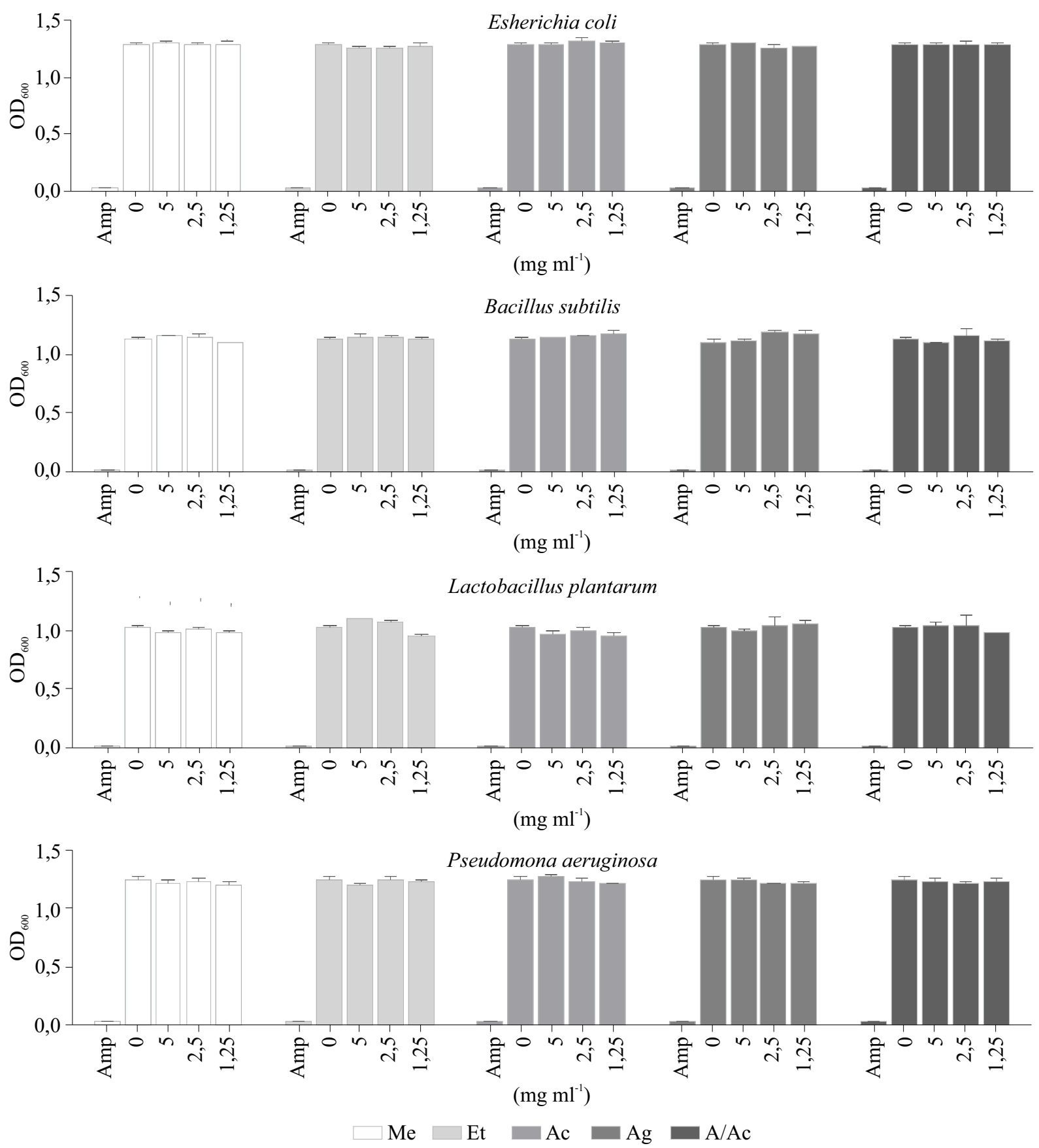

Figura 3. Actividad antimicrobiana de los extractos obtenidos a partir de los callos de vieiras. Concentración inhibitoria mínima determinada por absorbancia a $600 \mathrm{~nm}$. Media de los duplicados \pm DE. Me: metanol, Et: etanol, Ac: acetona, Ag: agua, A/Ac: ácido acético/acetona, Amp: ampicilina, control positivo, OD: densidad óptica.

Figure 3. Antimicrobial activity of extracts obtained from scallop muscles. Minimum inhibitory concentration determined by absorbance at $600 \mathrm{~nm}$. Mean of duplicates \pm SD. Me: methanol, Et: ethanol, Ac: acetone, Ag: water, A/Ac: acetic acid/acetone, Amp: ampicillin, positive control, OD: optical density. 
los callos fue comparable a la de un antibiótico comercial de amplio espectro. Si bien el método de extracción con agua es el mas económico, también es el más susceptible de sufrir contaminación por proliferación de bacterias presentes en los tejidos utilizados durante el tiempo de duración del proceso. Se recomienda utilizar etanol como método de extracción debido a su menor toxicidad que el metanol y la acetona, recuperación del solvente, y baja posibilidad de contaminación bacteriana durante el proceso, comparado con el método control (ácido acético/acetona) y con el método que utiliza agua en el proceso.

Este estudio representa una línea de partida para la obtención de extractos peptídicos no solo de otros bivalvos, sino también a partir de otros organismos que posean bajo valor comercial o son descartados en la pesca. Aquí se detalla un método simple, rápido y económico, con la posibilidad de ser adaptado a una mayor escala. A partir de estos resultados, el siguiente paso será purificar estos péptidos, identificarlos, determinar las fracciones que poseen la mayor actividad antimicrobiana, y evaluarlos como potenciales antibióticos para la industria farmacéutica, alimentaria, e incluso para su aplicación en acuicultura.

\section{AGRADECIMIENTOS}

Al Lic. Matías Schwartz por facilitar las muestras de vieira y a la Dra. María Inés Trucco por sus correcciones y colaboración en la revisión del trabajo. Contribución INIDEP N ${ }^{\circ} 2218$.

\section{REFERENCIAS}

Abouzeed YM, Zgheel F, Elfahem AA, Almarghe M, Dhawi A, Elbazl A, Hiblu MA, Kammon A, AHMwd MO. 2018. Identification of phenolic compounds, antibacterial and antioxidant activities of raisin extracts. Open Vet J. 8 (4): 479-484.

BAHAR AA, REN D. 2013. Antimicrobial peptides. Pharm. 6: 1543-1575.

Boullet $\mathrm{H}$, Bentot $\mathrm{F}$, Hequet A, GanemElbanz C, Bechara C, Pacreau E, Launay P, Sagan S, Jolivat C, Lacombe C, et al. 2019. Small antimicrobial peptide with in vivo activity against sepsis. Molecules. 24: 1702.

Campodónico S, Escolar M, García J, Aubone A. 2019. Síntesis histórica y estado actual de la pesquería de vieira patagónica Zygochlamys patagonica (King 1832) en la Argentina. Biología, evaluación de biomasa y manejo. Mar Fish Sci. 32 (2): 125-148.

[CLSI]. Clinical and Laboratory Standards InSTITUTE. 2012. Methods for dilution antimicrobial susceptibility tests for bacteria that grow aerobically; approved standard - Ninth Edition. CLSI document M07-A9.

DunNETT C. 1955. A Multiple Comparison Procedure for Comparing Several Treatments with a Control. J Am Stat Assoc. 50: 1096-1121.

Ennaas N, Hammami L, Beaulieu I, Fliss I. 2015. Purification and characterization of four antibacterial peptides from protames hydrolysate of Atlantic mackerel (Scomber scombrus) by-products. Biochem Biophys Res Commun. 462 (3): 195-200.

Geis J, Singh J, Teuber M. 1983. Potential of lactic streptococci to produce bacteriocin. Appl Environ Microbiol. 45 (1): 205-211.

Gutiérrez P, Orduz S. 2003. Péptidos antimicrobianos: estructura, función y aplicaciones. Actual Biol. 25 (78): 5-15.

Hancock Rew, Brown KL, MookherJeE N. 2006. Host defence peptides from invertebrates - emerging antimicrobial strategies. Immunobiology. 211: 315-322.

Hou Y, Wu X, Dai Z Wang G, Wu G. 2017. Protein hydrolysates in animal nutrition: Industrial production, bioactive peptides, and functional significance. J Anim Sci Biotechno. 8: 24. 
Injal A, Kshirsagar S, Dev M, Parkar K, KaZi A, Chavan M, Kulkarni AS. 2016. Antimicrobial activity of extracts of hepatopancreas and mucus of bivalve, Meretrix meretrix. European J Biotechnol Biosci. 4: 36-38.

Kafle JK, Bhardwaj B, Kaur R, Kumar D, BANARJEE D. 2018. A staining protocol of proteins on agarose gel with amido black. Acta Sci Med. Sciences. 7: 59-63.

Kim SK, MEndis E. 2006. Bioactive compounds from marine processing byproducts - A review. Food Res Int. 39: 383-393.

Kim R, Yокота H, Kim SH. 2000. Electrophoresis of proteins and protein/protein complexes in a native agarose gel. Anal Biochem. 282: 149-153.

Kiran N, Siddiqui G, Khan AN, Tushar P. 2014. Extraction and screening of bioactive compounds with antimicrobial properties from selected species of mollusk and crustacean. J Clin Cell Immunol. 5: 1.

Kuppusamy R, Willcox M, Black DS, Kumar N. 2019. Short cationic peptidomimetic antimicrobials. Antibiotics. 8: 44.

Lemus M, Salazar R, Lapo B, Chung K. 2016. Metalotineínas en bivalvos marinos. Lat Am J Aquat Res. 44: 202-215.

LonZA Research. 2019. Section XIII: Protein Separation in Agarose Gels. https://www.lonza. com/research.

Lordan S, Paul Ross R, Stanton C. 2011. Marine bioactives as functional food ingredients: potential to reduce the incidence of chronic diseases. Mar Drugs. 9: 1056-1100.

NAJAFIAN RL, BABJI AS. 2012. A review of fishderived antioxidant and antimicrobial peptides: Their production, assessment, and applications. Peptides. 33: 178-185.

Niu L, Zhang H, Wu Z, Wang Y, Liu H, Wu X, WANG, W. 2019. Modified TCA/acetone precipitation of plant proteins for proteomic analysis. PLoS One. 14(1):e0211612. doi: 10.1371/journal.pone.0211612
Pachaiyappan A, Sadhasivam G, Kumar M, Muthuvel A. 2014. Antibacterial activity of different solvent extracts of marine bivalve, Meretrix casta. Curr Biotica. 8: 270-277.

Ryan JT, Paul Ross R, Bolton D, Fitzgeral GF, Stanton C. 2011. Bioactive peptides from muscle sources: meat and fish. Nutrients. 3: 765-791.

Salomone AL, Massa AE. 2018. Evaluación de la capacidad antimicrobiana de hidrolizados enzimáticos obtenidos a partir de subproductos de merluza. Inf. Invest INIDEP $\mathrm{N}^{\circ}$ 10/2018. 11 p.

Schwartz M, Campodónico MS. 2017. Primera descripción del desarrollo embrionario y larval temprano de la vieira patagónica (Zygochlamys patagonica). Inf Invest INIDEP $\mathrm{N}^{\circ}$ 105/2017. 10 p.

Shahidi F, Zhong Y. 2008. Bioactive peptides. J AOAC Int. 9: 914-31.

Sharma S, Chatterji A, Das P. 2009. Effect of different extraction procedures on antimicrobial activity of marine bivalves: a comparison. Pertanika J Trop Agric Sci. 32: 77-83.

Sugesh S, Mayavu P. 2013. Antimicrobial activities of two edible bivalves $M$. meretrix and $M$. casta. Pak J Biol Sci. 16: 38-43.

TAN SC, YIAP BC. 2009. DNA, RNA, and protein extraction: the past and the present. J Biomed Biotechnol. doi:10.1155/2009/574398

THERMO Fisher SCIENTIFIC INC. 2009. Acetone precipitation of proteins. TR0049.1. https:// www.thermo.com/pierce.

Tincu JA, TAYlor SW. 2004. Antimicrobial peptides from marine invertebrates. Antimicrob. Agents Chemother. 48: 3645-3654.

Wang X, Yu H, Xing R, Li P. 2017. Characterization, preparation, and purification of marine bioactive peptides. Hindawi BioMed Res Int. Article ID 9746720.

Wu M, Kusukawa N. 1998. SDS Agarose Gels for Analysis of Proteins. BioTechniques. 24: 676-678. 
